\title{
Association of ANRIL Polymorphism With Overall Survival in Adult Patients With Hematologic Malignancies After Allogeneic Hematopoietic Stem Cell Transplantation
}

\author{
JUNAN LI ${ }^{1,2}$, NATHAN SELIGSON ${ }^{1,3}$, XUEJIE ZHANG ${ }^{1}$, JASMINE JOHNSON $^{1}$, ZACHARY VANGUNDY $^{1}$, \\ DANXING WANG ${ }^{4}$, MITCH PHELPS ${ }^{2,5}$, CRAIG HOFMEISTER $^{6}$, WOLFGANG SADEE ${ }^{7}$ and MING JING POI ${ }^{1,2,3}$ \\ ${ }^{1}$ Division of Pharmacy Practice and Science, College of Pharmacy, \\ The Ohio State University, Columbus, OH, U.S.A; \\ ${ }^{2}$ Comprehensive Cancer Center, The Ohio State University, Columbus, Ohio, U.S.A; \\ ${ }^{3}$ Department of Pharmacy, The Ohio State University Wexner Medical Center, Columbus, OH, U.S.A; \\ ${ }^{4}$ Department of Pharmacotherapy and Translational Research, \\ College of Pharmacy, University of Florida, Gainesville, FL, U.S.A; \\ ${ }^{5}$ Division of Pharmaceutics and Pharmaceutical Chemistry, College of Pharmacy, \\ The Ohio State University, Columbus, OH, U.S.A; \\ ${ }^{6}$ Department of Hematology \& Oncology, Winship Cancer Institute of Emory University, Atlanta, GA, U.S.A; \\ ${ }^{7}$ Department of Cancer Biology and Genetics, Center for Pharmacogenomics, \\ College of Medicine, The Ohio State University, Columbus, OH, U.S.A.
}

\begin{abstract}
Background/Aim: Genetic variations of the noncoding RNA gene, ANRIL, have been associated with human diseases including cancer, type-2 diabetes, and atherosclerosis. In the present study, we investigated the potential associations of select ANRIL single nucleotide polymorphisms (SNPS) with overall survival and other clinical outcomes in adult patients with hematologic malignancies after allogeneic hematopoietic stem cell transplantation (allo-HSCT). Patients and Methods: Genomic DNA was extracted from whole blood samples from 103 adult patients with hematologic malignancies who had received allo-HSCT followed by oral tacrolimus therapy. The genotypes of four select ANRIL SNPs, rs564398, rs1063192, rs2151280, and rs2157719 were determined using qRT-PCRbased genotyping assays. Results: rs2151280 (C->T) in ANRIL was associated with worse overall survival in these patients (CT/CC vs. TT). Contrarily, rs2151280 and the other select ANRIL SNPs were not associated with death at Day-100 after transplantation, the incidence of graft-versus-host disease $(G V H D)$, acute kidney injury (AKI), and neurotoxicity in the
\end{abstract}

This article is freely accessible online.

Correspondence to: Junan Li, Ph.D., College of Pharmacy, The Ohio State University, Columbus, OH 43210, U.S.A. Tel: +1 6242921036, Fax:+1614292-2588, e-mail: 1i.225@osu.edu.

Key Words: ANRIL, single nucleotide polymorphism, ARF-INK4 locus, hematologic malignancies, allogeneic hematopoietic stem cell transplantation. study cohort. Conclusion: rs2151280 represents a potential prognostic biomarker for overall survival in adult patients with hematologic malignancies after allo-HSCT.

Chromosome 9p21 harbors the ARF-INK4 locus, which encodes three tumor suppressive proteins, p15 ${ }^{\mathrm{INK} 4 \mathrm{~B}}(\mathrm{P} 15)$, p16 ${ }^{\mathrm{INK} 4 \mathrm{~A}}$ (P16) and p14ARF (ARF) (1-5). P15 and P16 specifically inhibit cyclin D-dependent kinase 4 (CDK4)mediated phosphorylation of retinoblastoma protein (pRB), thus regulating cell cycle progression; ARF inhibits the ability of mouse double minute 2 homolog (MDM2) to suppress p53, and consequently promotes apoptosis or cell cycle arrest $(4,5)$. Recent studies have demonstrated that the non-coding RNA ANRIL (also designated as CDKN2BAS) is located adjacent to the INK4-ARF locus but is transcribed in the antisense direction with respect to p14ARF (6-9). ANRIL interacts with polycomb repressing complexes 1 and 2 (PRC1 and 2), and negatively regulates the transcription of the entire INK4-ARF locus (10-12). Emerging evidence has revealed that some single nucleotide polymorphisms (SNPs) in ANRIL are associated with susceptibility to the development of human diseases, including different types of cancer, type-2 diabetes and atherosclerosis (9, 13-26). Specifically, rs564398 has frequently been found in patients with leukemia and esophageal squamous cell carcinoma (ESCC). ANRIL rs2151280 has been associated with increased risk of developing lung cancer and basal cell carcinoma (BCC) while rs1063192 and rs2157719 have been correlated with glioma, brain cancer, and ESCC. Additionally, our previous study has demonstrated that 
rs2151280 was associated with mRNA expression of $p 15$, p16, and $A R F$ in peripheral blood mononuclear cells (PBMCs) from multiple myeloma patients, and with progression-free survival (PFS) following autologous stem cell transplantation (27). Taken together, these findings imply that ANRIL SNPs may impact the development and treatment of human hematologic malignancies.

In this study, we determined the geneotypes of four previously reported cancer-related ANRIL SNPs, rs564398, rs1063192, rs2151280, and rs2157719 using whole blood DNA samples from 103 adult patients with hematologic malignancies and evaluated their associations with patient overall survival (OS) following allogeneic hematopoietic stem cell transplantation (allo-HSCT). Our results showed that ANRIL rs2151280 alone was associated with OS in the study cohort.

\section{Patients and Methods}

Study population. The study population was from a single-institution research protocol to study the pharmacokinetics and pharmacogenomics of tacrolimus and their association with clinical outcomes in allo-HSCT patients. One hundred and three adult patients receiving oral tacrolimus for the prevention of GVHD following allo-HSCT at The Ohio State University Wexner Medical Center were prospectively enrolled following approval from the Institutional Review Board (IRB \#2012C0021). Inclusion criteria included age greater than 18 years, patients receiving their first alloHSCT during the study period, and absence of renal or hepatic dysfunction at baseline. Exclusion criteria included HIV positivity, presence of any medical conditions that would interfere with the patient's ability to provide informed consent, hypersensitivity to any components of tacrolimus, clinical history of any solid organ transplantation, previous chronic use of tacrolimus, and pregnancy.

Genomic DNA extraction and genotyping assays. Genomic DNA was extracted from patient's whole blood sample using the DNAeasy Blood mini kit (Qiagen, Valencia, CA, USA) following the manufacturer's instructions. RNase A was included in the purification procedure to remove potential RNA contamination as recommended by the manufacturer. After quantitation using UV spectrometry, DNA samples were stored at $-80^{\circ} \mathrm{C}$ for future use.

Genotypes of four select ANRIL SNPs, rs564398, rs2151280, rs 1063192 , and rs2157719 were determined as previously described (27).

Statistical analyses. Demographic and clinical characteristics of patients were analyzed using descriptive statistics. Characteristics were compared using Student's $t$-tests, $\chi^{2}$ tests or Fisher's exact tests where appropriate.

The consistency between the distribution of each ANRIL SNP in the study cohort and the Hardy-Weinberg principle and the potential nonrandom allele associations between selected SNPs were analyzed using $\chi^{2}$ tests.

Patients without known death/alive information were censored at the date of last follow up. Time to death, the time from transplant (Time 0) until death, was analyzed using Kaplan-Meier curves followed by the log-rank test. Multivariate analysis was conducted using the proportional hazard regression model of Cox (Cox PH regression) and a stepwise backward approach was applied for model reduction. The final proportional hazard regression model included factors with $p$-values less than 0.05 and was justified as previously described (28).

Potential associations between ANRIL SNPs and the incidence of death at Day-100 post transplant, GVHD, AKI, and neurotoxicity were evaluated using competing risks regression in which death was a competitive risk factor for GVHD, AKI, and neurotoxicity (29). All statistical analyses were conducted using R3.5 .0 (R Foundation for Statistical Computing). $p$-Values were two-sided, and unless specified, $p$-values values of less than 0.05 were regarded as statistically significant.

\section{Results}

Patients. Table I summarizes the demographic characteristics of 103 patients included in this study. The mean age at transplant of this patient cohort was 55.6 years $( \pm 11.8$ years), and 46 patients $(44.7 \%)$ were older than 65 years of age. Additionally, 64 patients $(62.1 \%)$ were male while 88 patients were Caucasian $(85.4 \%)$. Sixty-seven patients $(65 \%)$ were newly diagnosed at time of study entry. Disease diagnosis varied and $41(49.8 \%), 8(7.7 \%), 8(7.7 \%)$, and $7(6.8 \%)$ patients diagnosed with AML, ALL, DLBCL, and myelofibrosis, respectively. Eighty-nine patients $(86.3 \%)$ received matched transplants, including matched sibling and matched unrelated donors, while 1 patient received a mismatched unrelated transplant. The remaining patients received cells from umbilical cord donors (13 of 103, 12.8\%).

No significant associations were found between age, gender, race, risk score, the ECOG performance score, comorbidity score, baseline $\mathrm{SCr}$, baseline $\mathrm{CrCL}$, and weight-adjusted starting tacrolimus dose. The one exception was a correlation between ECOG performance score and comorbidity score. Patients with higher comorbidity scores $(\geq 3)$ were more likely to have higher ECOG scores (1 and 2) than patients with low comorbidity scores $(0-2)(p=0.007)$. This is consistent with previous studies showing that the ECOG score significantly increased in cancer patients with comorbidities in comparison with patients without comorbidities (30).

ANRIL SNPs in patients. A number of ANRIL SNPs have recently been associated with the development and treatment of human cancers. Four of these SNPs, ss564398, rs2151280, rs 1063192, and rs2157719, were investigated in this study due to their reported correlations with human cancers (1316, 23-27).

Table II summarizes the genotypes of the 4 ANRIL SNPs in this study cohort. The minor allele frequencies (MAFs) for these four SNPs were approximately $40 \%$, and the genotype distributions of these SNPs followed the HardyWeinberg principle (all $p$-values $>0.9$ ) (27). For rs2151280, $31.1 \%(n=32), 49.5 \%(n=51)$, and $19.4 \%(n=20)$ of patients were homozygous for the major allele (genotype: CC; ancestral allele), heterozygous (genotype: TC), and 
Table I. Demographic and clinical characteristics of patients included in this study (N=103).

\begin{tabular}{lc}
\hline Characteristics & Values \\
\hline Age (year) & \\
Mean (SD) & $55.6(11.8)$ \\
Median (IQR) & $58.9(13.9)$ \\
$>65$ & $46(44.7 \%)$ \\
Gender & \\
Female & $39(37.9 \%)$ \\
Male & $64(62.1 \%)$ \\
Race & \\
Caucasian & $88(85.4 \%)$ \\
Non-Caucasian & $15(14.6 \%)$ \\
Disease type & \\
Acute myeloid leukemia & $41(39.8 \%)$ \\
Acute lymphoblastic leukemia & $8(7.7 \%)$ \\
Diffuse large B-cell lymphoma & $8(7.7 \%)$ \\
Myelofibrosis & $7(6.8 \%)$ \\
Other & $39(38 \%)$ \\
Disease stage & \\
Newly diagnosed & $67(65.0 \%)$ \\
Relapsed & $36(35.0 \%)$ \\
Transplant type & \\
Matched sibling & $35(33.9 \%)$ \\
Matched unrelated & $54(52.4 \%)$ \\
Mismatched unrelated & $1(0.9 \%)$ \\
Umbilical cord & $13(12.8 \%)$ \\
Cell source & \\
Peripheral blood stem cell transplants & $88(85.4 \%)$ \\
Bone marrow & $2(1.9 \%)$ \\
Umbilical cord & $13(12.8 \%)$ \\
Comorbidity index & \\
0 & $14(13.6 \%)$ \\
1 & $7(6.8 \%)$ \\
2 & $19(18.4 \%)$ \\
3 & $21(20.4 \%)$ \\
5 & $20(19.4 \%)$ \\
ECOG ab score & $22(21.4 \%)$ \\
0 & \\
1 & $46(44.7 \%)$ \\
2 & $55(53.4 \%)$ \\
\hline & $2(1.9 \%)$ \\
\hline
\end{tabular}

\begin{tabular}{lc}
\hline Characteristics & Values \\
\hline Risk score & \\
1 & $3(2.9 \%)$ \\
2 & $16(15.5 \%)$ \\
3 & $43(41.7 \%)$ \\
4 & $9(8.7 \%)$ \\
5 & $15(14.6 \%)$ \\
6 & $17(16.5 \%)$ \\
Baseline CrCL (ml/min) & \\
Mean (SD) & $62.7(21.7)$ \\
Median (IQR) & $59.8(24.6)$ \\
Baseline SCr (mg/dl) & \\
Mean (SD) & $0.73(0.21)$ \\
Median (IQR) & $0.70(0.23)$ \\
Starting tacrolimus dose (mg/kg) & \\
Mean (SD) & $0.047(0.011)$ \\
Median (IQR) & $0.046(0.007)$ \\
AKI & \\
No & $40(38.8 \%)$ \\
Yes & $63(61.2 \%)$ \\
GVHD grade & \\
0 & $52(50.5 \%)$ \\
1 & $22(21.4 \%)$ \\
2 & $23(22.3 \%)$ \\
3 and above & $6(5.8 \%)$ \\
Neurotoxicity & \\
No & $80(77.7 \%)$ \\
Yes & $23(22.3 \%)$ \\
Death during 100 days after transplantation & \\
No & $92(89.3 \%)$ \\
Yes & $11(10.7 \%)$ \\
Neath during the study period & \\
Yes & $53(51.5 \%)$ \\
\hline & $50(48.5 \%)$ \\
\hline
\end{tabular}

AKI: Acute kidney injury; CrCL: creatinine clearance; ECOG: the Eastern Cooperative Oncology Group performance score; GVHD: graftversus-host disease; IQR: inter-quartile range (from $1^{\text {st }}$ quartile to $3^{\text {rd }}$ quartile); SCr: serum creatinine; SD: standard deviation.

homozygous for the minor allele (genotype: TT; variant), respectively. Further analyses showed that all four ANRIL SNPs were in significant LD (linkage disequilibrium) with each other in our study cohort (all $p$ values $<0.01$ ), primarily ascribed to their close chromosomal proximity (27).

rs2151280 is associated with overall survival after allo-HSCT. We then evaluated the potential associations between patient characteristics and OS in the study cohort using univariate and multivariate survival analyses (Table III). Of the 103 patients, 50 (48.5\%) died during the study period. The median time to follow-up was 1084 days (date of transplant time was defined as Time 0). Survival analyses using univariate models showed statistically significant associations with OS between age ( $>65$ vs. $\leq 65 ; \mathrm{HR}=2.21,95 \% \mathrm{CI}=1.26-3.88, p=0.006)$ and comorbidity score ( $\geq 3$ vs. $0-2 ; \mathrm{HR}=2.09,95 \% \mathrm{CI}=1.13-3.88, p=0.02)$. Moreover, ANRIL rs2151280 (CT/CC vs. TT) and disease type (AML vs. Other) were associated with OS with borderline significance (for $\mathrm{rs} 2151280, \mathrm{HR}=0.55,95 \% \mathrm{CI}=0.29-1.04$, $p=0.07$; for disease type, $\mathrm{HR}=1.66,95 \% \mathrm{CI}=0.95-2.89, p=0.075$ ), whereas rs564398 (CC vs. CT/TT) and risk score (1-3 vs. $\geq 4)$ tended to be associated with OS (for rs564398, HR=0.42, $95 \% \mathrm{CI}=0.13-1.35, \quad p=0.15 ; \quad$ for risk score, $\mathrm{HR}=0.63$, $95 \% \mathrm{CI}=0.35-1.14, p=0.14)$. The median time to death for rs2151280 TT patients was 379 days. In contrast, the median time to death for rs2151280 TC/CC patients was >1300 days; thus, median survival was not achieved during the study period (Figure 1). Furthermore, no association was observed between 
Table II. Genotypes of the 4 selected ANRIL SNPs in patients included in this study (N=103).

\begin{tabular}{|c|c|c|c|c|c|c|c|c|c|c|}
\hline \multirow[t]{2}{*}{ SNP } & \multicolumn{6}{|c|}{ Genotype } & \multicolumn{3}{|c|}{ Allele } & \multirow[t]{2}{*}{$p$-Value $* * *$} \\
\hline & $\mathrm{M} / \mathrm{M}$ & $\mathrm{n}_{1} *$ & $\mathrm{M} / \mathrm{m}$ & $\mathrm{n}_{2} *$ & $\mathrm{~m} / \mathrm{m}$ & $\mathrm{n}_{3} *$ & $M^{* *}$ & $m^{* *}$ & MAF & \\
\hline rs564398 & $\mathrm{T} / \mathrm{T}$ & 42 & $\mathrm{~T} / \mathrm{C}$ & 49 & $\mathrm{C} / \mathrm{C}$ & 12 & 133 & 73 & 0.354 & 0.96 \\
\hline rs 1063192 & $\mathrm{~A} / \mathrm{A}$ & 39 & $\mathrm{~A} / \mathrm{G}$ & 47 & $\mathrm{G} / \mathrm{G}$ & 17 & 125 & 81 & 0.393 & 0.95 \\
\hline rs 2151280 & $\mathrm{C} / \mathrm{C}$ & 32 & $\mathrm{C} / \mathrm{T}$ & 51 & $\mathrm{~T} / \mathrm{T}$ & 20 & 115 & 91 & 0.442 & 0.99 \\
\hline rs2157719 & $\mathrm{T} / \mathrm{T}$ & 39 & $\mathrm{~T} / \mathrm{C}$ & 49 & $\mathrm{C} / \mathrm{C}$ & 15 & 127 & 79 & 0.383 & 0.99 \\
\hline
\end{tabular}

*The number of patients (n) with specific genotypes. M: Major allele; m: minor allele. **The number of patients with specific alleles. MAF: Minor allele frequency. $* * * \chi^{2}$ tests were used to analyze the consistency between the actual genotype distribution and the Hardy-Weinberg principle. $p$-Values of less than 0.05 indicate that the actual genotype distribution significantly deviates from the Hardy-Weinberg principle.

Table III. Univariate and multivariate analyses of overall survival (OS) of patients included in this study ( $n=103)$.

\begin{tabular}{|c|c|c|c|}
\hline Characteristics & $\mathrm{HR}^{*}$ & $95 \% \mathrm{CI}^{*}$ & $p$-Value** \\
\hline \multicolumn{4}{|l|}{ Univariate } \\
\hline rs564398 (CT/TT vs. CC) & 0.42 & {$[0.74,7.69]$} & 0.15 \\
\hline rs $1063192(A G / G G v s . A A)$ & 0.86 & {$[0.65,2.08]$} & 0.62 \\
\hline rs2151280 (CT/CC vs. TT) & 0.55 & {$[0.29,1.04]$} & 0.07 \\
\hline rs2157719 (CT/TT vs. CC) & 0.54 & {$[0.73,4.55]$} & 0.20 \\
\hline age $(>65 v s . \leq 65)$ & 2.21 & {$[1.26,3.88]$} & 0.006 \\
\hline gender (Male $v s$. Female) & 0.98 & {$[0.56,1.74]$} & 0.96 \\
\hline Race (Caucasian vs. non-Caucasian) & 0.90 & {$[0.40,2.00]$} & 0.79 \\
\hline ECOG $(1 / 2 v s .0)$ & 1.52 & {$[0.86,2.69]$} & 0.15 \\
\hline Comorbidity (3 and above vs. $0-2$ ) & 2.09 & {$[1.13,3.88]$} & 0.02 \\
\hline Risk score (1-3 vs. 4 and above) & 0.63 & {$[0.35,1.14]$} & 0.13 \\
\hline Disease stage (Relapsed vs. Newly diagnosed) & 0.66 & {$[0.35,1.22]$} & 0.18 \\
\hline Disease type (AML $v s$. other) & 1.66 & {$[0.95,2.89]$} & 0.075 \\
\hline Starting dose of Tacrolimus per $\mathrm{kg}$ weight Increasing by $1 \mathrm{mg} / \mathrm{kg}$ ) & 0.0023 & {$[0.0001,>10,000]$} & 0.67 \\
\hline Baseline creatinine clearance Increasing by $1 \mathrm{ml} / \mathrm{min}$ & 0.99 & {$[0.98,1.01]$} & 0.26 \\
\hline Baseline serum creatinine Increasing by $1 \mathrm{mg} / \mathrm{dl}$ & 0.74 & {$[0.20,2.69]$} & 0.64 \\
\hline \multicolumn{4}{|l|}{ Multivariate*** } \\
\hline rs2151280 (CT/CC vs. TT) & 0.44 & {$[0.22,0.85]$} & 0.015 \\
\hline age $(>65$ vs. $\leq 65)$ & 2.24 & {$[1.27,3.94]$} & 0.005 \\
\hline Comorbidity (3 and above vs. $0-2$ ) & 2.57 & {$[1.35,4.89]$} & 0.004 \\
\hline
\end{tabular}

*HR: Hazard ratio; CI: confidence interval. **p-values from proportional hazard Cox regression analyses. ***The overall $p$-value for this multivariate model was $<0.0001$.

OS and race, disease stage (relapsed vs newly diagnosed), baseline renal function (baseline CrCL), and starting tacrolimus dose (all $p$-values $>0.20$ ). In addition, there are no statistically significant differences in the characteristics of the patients harboring rs2151280 TC/CC and TT genotypes (data not shown).

Further multivariate analyses revealed that rs2151280, age, and comorbidity remained significantly associated with OS in this patient cohort (with $p$-values $<0.05$ ). After adjustment for age and comorbidity, the HR between the rs $2151280 \mathrm{CT} / \mathrm{CC}$ group and the rs2151280 TT group was 0.44 (95\%CI=0.22$0.85, p=0.015$ ), suggesting that patients with rs $2151280 \mathrm{TT}$ genotype have higher risk for death after allo-HSCT. The adjusted HRs for age (Age $>65 v s$. Age $\leq 65)$ and comorbidity ( $\geq 3$ vs. $0-2)$ were $2.24(95 \% \mathrm{CI}=1.27-3.94, p=0.005)$ and 2.57 (95\% CI $=1.35-4.89, p=0.004)$, respectively. These findings are consistent with previous studies associating advanced age and presence of comorbidities with poor prognosis (30). Taken together, rs2151280 TT appears to be a potential prognostic factor (in addition to age and comorbidity score) for OS of leukemia patients after allo-HSCT.

Impact of ANRIL SNPs on other clinical outcomes in patients with allo-HSCT. Lastly, we explored the potential associations between the aforementioned ANRIL SNPs and the incidence of 

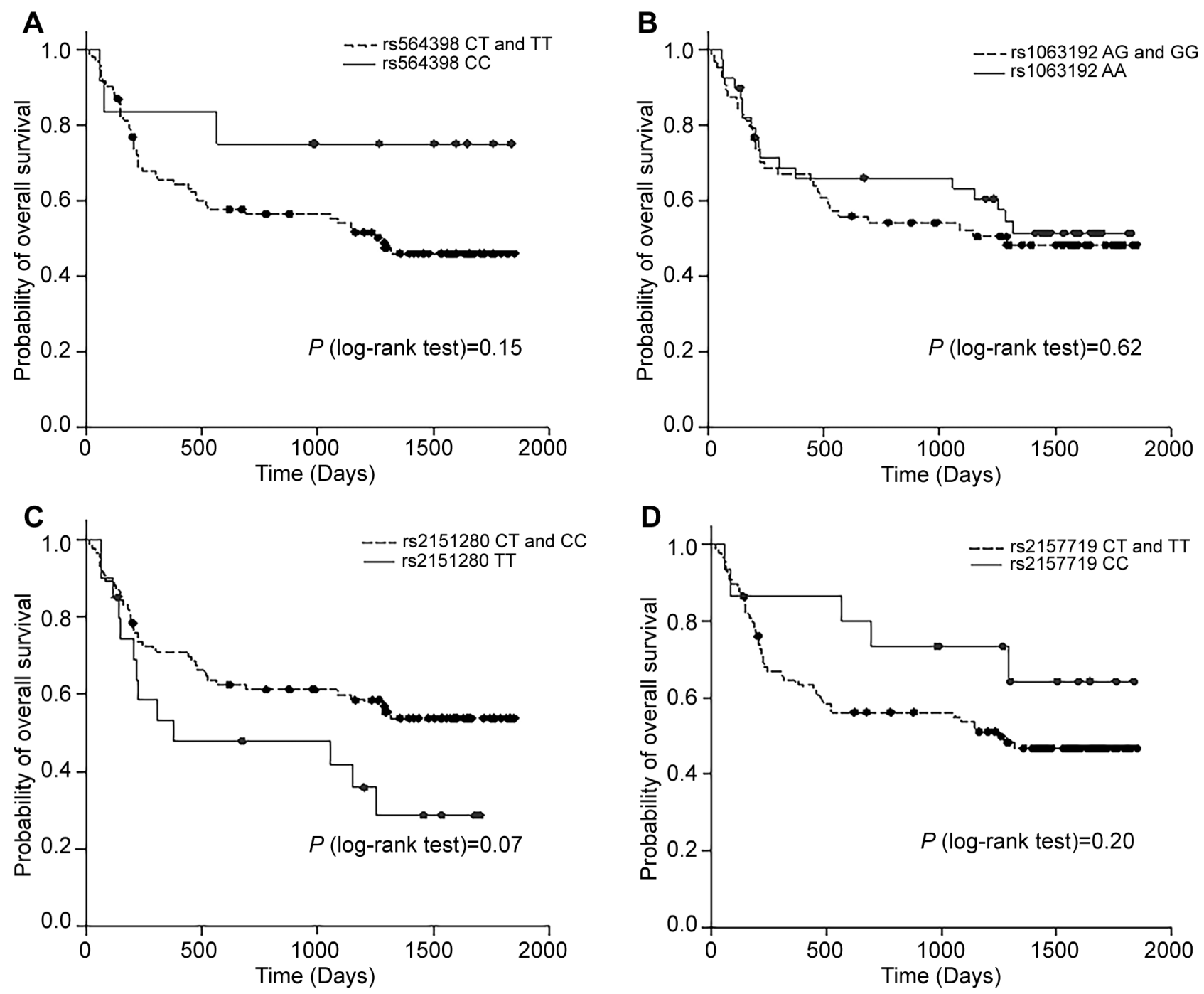

Figure 1. Kaplan-Meier curves showing the overall survival of 103 patients with different ANRIL genotypes in the four select SNPs following allogeneic hematopoietic stem cell transplantation. Patients with different genotypes were compared using the log-rank tests. A, rs564398 (CT+TT vs. CC); B, rs1063192 (AG+GG vs. AA); C, rs2151280 (CT+CC vs. TT); D, rs2157719 (CT+TT vs. CC).

death at Day-100, GVHD, AKI, and neurotoxicity in the study cohort. Our results showed that none of the select ANRIL SNPs was associated with death at Day-100. Similarly, no statistically significant correlation was observed between these genetic alterations and GVHD or AKI (all $p$-values $>0.20$ ). Instead, gender, comorbidity and baseline CrCL were statistically associated with AKI ( $p=0.015,0.012$, and 0.0006 , respectively).

\section{Discussion}

In the current study, we revealed that ANRIL rs2151280 was significantly associated with OS in adult patients with hematologic malignancies after allo-HSCT. Patients harboring the rs $2151280 \mathrm{TT}$ genotype tend to have poorer
OS. The underlying mechanism could be ascribed to ANRILmediated transcription suppression on the entire $A R F-I N K 4$ gene $(7,11,12)$. Our previous study had shown that rs2151280 SNP leads to elevated expression of ANRIL in PBMCs from multiple myeloma patients, and such increase in ANRIL expression simultaneously downregulated the mRNA expression of $p 15, p 16, A R F$ in PBMCs (27). Presumably, patients homozygous for rs2151280 TT would have decreased expression of ARF, which further negatively impacts p53-mediated apoptosis in patients with hematologic malignancies. Similarly, reduced expression of $p 16$ and $p 15$ in rs2151280 TT patients could down-regulate pRB-mediated cell-cycle control, promoting tumor progression or relapse. Hence, both p53 and pRB pathways in patients harboring 
rs2151280 TT could be impaired $(27,31)$, thus influencing the clinical outcomes in adult patients with hematologic malignancies.

There are several limitations in this study. First, the patient cohort was relatively small, and statistical comparisons were performed between two "unbalanced" groups (20 rs2161280 $T T$ patients vs. 83 rs2151280 TC+CC patients). Moreover, the study cohort included diverse hematologic malignancies, such as AML, ALL, DLBCL, and myelofibrosis. The molecular mechanisms underlying these hematologic malignancies as well as their clinical outcomes vary considerably $(32,33)$. Accordingly, a large cohort of patients would be required to stratify patients based on specific hematologic malignancy. Second, this was a retrospective study and only whole blood DNA specimens were available for genotyping and genetic alteration analyses, precluding analysis of rs2151280 TT association with mRNA and protein expression of $p 15, p 16$, and ARF in blood. Lastly, the impact of ANRIL SNPs other than the select four were not determined. Regardless of these limitations, our results provide a foundation for better understanding the role of genomic variants in ANRIL in patients with hematologic malignancies after allogeneic hematopoietic stem cell transplantation.

\section{Conflicts of Interest}

The Authors declare no conflicts of interest in relation to this study.

\section{Authors' Contributions}

MJP and WS contributed to the study design; JL, NS, XZ, JJ, ZV performed experiments and collected data; JL and MP analyzed the data and prepared the manuscript; MJP, WS, MP, and $\mathrm{CH}$ contributed to the clinical trial; all co-authors reviewed and approved the final version of the manuscript for submission.

\section{Acknowledgements}

This study was partly supported by a research grant from NIH, NIGMS/U01 GM092655 (WS) and a startup fund from The Ohio State University College of Pharmacy (MJP).

\section{References}

1 Ortega S, Malumbres M and Barnacid M: Cyclin D-dependent kinases: INK4 inhibitors and cancer. Biochim Biophys Acta 1602: 73-87, 2002. PMID: 11960696. DOI: 10.1016/s0304419x(02)00037-9

2 Li J, Poi MJ and Tsai MD: Regulatory mechanisms of tumor suppressor P16(INK4A) and their relevance to cancer. Biochemistry 50(25): 5566-5582, 2011. PMID: 21619050. DOI: 10.1021/bi200642e

3 Gil J and Peters G: Regulation of the INK4b-ARF-INK4a tumor suppressor locus: all for one or one for all. Nat Rev Cell Biol 7(9): 667-677, 2006. PMID: 16921403. DOI: 10.1038/ nrm1987
4 Sherr CJ: Ink4-Arf locus in cancer and aging. WIRE Dev Biol 1(5): 731-741, 2012. PMID: 22960768. DOI: 10.1002/wdev.40

5 Kim WY and Sharpless NE: The regulation of INK4/ARF in cancer and aging. Cell 127(2): 265-275, 2006. PMID: 17055429. DOI: $10.1016 /$ j.cell.2006.10.003

6 Popov N and Gil J: Epigenetic regulation of the INK4b-ARFINK4a locus: in sickness and in health. Epigenetics 5(8): 685690, 2010. PMID: 20716961. DOI: 10.4161/epi.5.8.12996

7 Pasmant E, Laurendeau I, Héron D, Vidaud M, Vidaud D and Bieche I: Characterization of a germ-line deletion, including the entire INK4/ARF locus, in a melanoma-neural system tumor family: identification of ANRIL, an antisense noncoding RNA whose expression coclusters with ARF. Cancer Res 67(8): 39633969, 2007. PMID: 17440112. DOI: 10.1158/0008-5472.CAN06-2004

8 Kotake Y, Naemura M, Murasaki C, Inoue Y and Okamoto H: Transcriptional regulation of the p16 tumor suppressor gene. Anticancer Res 35(8): 4397-4401, 2015. PMID: 26168478.

9 Li WQ, Pfeiffer RM, Hyland PL, Shi J, Gu F, Wang Z, Bhattacharjee S, Luo J, Xiong X, Yeager M, Deng X, Hu N, Talor P, Albanes D, Caporaso N, Gapstur S, Amundadottir A, Vhanock S, Chatterjee N, Landi M, Tucker M, Goldstein A and Yang X: Genetic polymorphisms in the 9p21 region associated with risk of multiple cancers. Carcinogenesis 35(12): 2698-2705, 2014. PMID: 25239644. DOI: 10.1093/carcin/bgu203

10 Maggi LB Jr., Winkeler CL, Miceli AP, Apicelli AJ, Brady SZ, Kuchenreuther MJ and Weber JD: ARF tumor suppression in the nucleolus. Biochim Biophys Acta 1842(6): 831-839, 2014. PMID: 24525025. DOI: 10.1016/j.bbadis.2014.01.016

11 Meseure D, Vacher S, Alsibai KD, Nicolas A, Chemlali W, Caly M, Lidereau R, Pasmant E, Callens C and Bieche I: Expression of ANRIL-Polycomb complexes-CDKNA/B/ARF genes in breast tumors: identification of a two-gene (EZH/CBX7) signature with independent prognostic value. Mol Cancer Res 14(7): 623-633, 2016. PMID: 27102007. DOI: 10.1158/15417786.MCR-15-0418

12 Aguilo F, Zhou MM and Walsh MJ: Long noncoding RNA, polycomb, and the ghost haunting INK4b-ARF-INK4a expression. Cancer Res 71(16): 5365-5369, 2011. PMID: 21828241. DOI: 10.1158/0008-5472.CAN-10-4379

13 Turnbull C, Ahmed S, Morrison J, Pernet D, Renwick A, Maranian M, Seal S, Ghoussaini M, Hines S, Healey CS, Hughs D, Warren-Perry M, Tapper W, Eccles D, Evans DG, Hooning M, Schutte M, van den Ouweand A, Houlston R, Rodd G, Langford C, Pharoah P, Stratton MR, Dunning AM, Rahman N and Eason DF: Genome-wide association study identifies fivenew breast cancer susceptibility loci. Nat Genet 42(6): 504507, 2010. PMID: 20453838. DOI: 10.1038/ng.586

14 Pasmant E, Sabbagh A, Vidaud M and Bieche I: ANRIL, a long, noncoding RNA, is an unexpected major hotspot in GWAS. FASEB J 25(2): 444-448, 2011. PMID: 20956613. DOI: $10.1096 /$ fj.10-172452

15 Cunnington MS, SantibanezKoref M, Mayosi BM, Burn J and Keavney B: Chromosome 9p21 SNPs associated with multiple disease phenotypes correlate with ANRIL expression. PLoS Genet 6(4): e1000899, 2010. PMID: 20386740. DOI: 10.1371/journal.pgen.1000899

16 Iacobucci I, Sazzini M, Garagnani P, Ferrari A, Boattini A, Lonetti A, Papayannidis C, Mantovani V, Marasco E, Ottaviani E, Soverini S, Girelli D, Luiselli D, Vignetti M, Baccarani M 
and Martinelli G: A polymorphism in the chromosome 9p21 ANRIL locus is associated to Philadelphia positive acute lymphoblastic leukemia. Leuk Res 35(8): 1052-1059, 2011. PMID: 21414664. DOI: 10.1016/j.leukres.2011.02.020

17 Burd CE, Jeck WR, Liu Y, Sanoff HK, Wang Z and Sharpless NE: Expression of linear and novel circular forms of an INK4/ARF-associated non-coding RNA correlates with atherosclerosis risk. PLoS Genet 6(12): e1001233, 2010. PMID: 21151960. DOI: 10.1371/journal.pgen.1001233

18 Congrains A, Kamide K, Oguro R, Yasuda O, Miyata K, Yamamoto E, Kawai T, Kusunoki H, Yamamoto H, Takeya Y, Yamamoto K, Onishi M, Sugimoto K, Katsuya T, Awata N, Ikebe $\mathrm{K}$, Gondo Y, Oike Y, Ojishi M and Rakugi H: Genetic variants at the 9p21 locus contribute to atherosclerosis through modulation of ANRIL and CDKN2A/B. Atherosclerosis 220(2): 449-455, 2012. PMID: 22178423. DOI: 10.1016/j.atherosclerosis.2011.11.017

19 Cugino D, Gianfagna F, Santimone I, de Gaetano E, Donati MB, Lacoviello L and Castelnuovo: Type 2 diabetes and polymorphisms on chromosome 9p21: a meta-analysis. Nutr Metab Cardiovasc Dis 22(8): 619-625, 2012. PMID: 21315566. DOI: 10.1016/j.numecd.2010.11.010

20 Ahmed W, Ali IS, Riaz M, Younas A, Sadeque A, Niazi AK, Niazi SH, Benish SH, Azam M and Qamar R: Association of ANRIL polymorphism (rs1333049:C>G) with myocardial infarction and its pharmacogenomic role in hypercholesterolemia. Gene 515(2): 416420, 2013. PMID: 23266621. DOI: 10.1016/j.gene.2012.12.044

21 Wan G, Mathur R, Hu X, Liu Y, Zhang X, Peng G and Lu X: Long non-coding RNA ANRIL (CDKN2B-AS) is induced by the ATM-E2F1 signaling pathway. Cell Signal 25(5): 1086-1095, 2013. PMID: 23416462. DOI: 10.1016/j.cellsig.2013.02.006

22 Liu Y, Sanoff HK, Cho H, Burd CE, Torrice C, Mohlke KL, Ibrahim JG, Thomas NE and Sharpless NE: INK4/ARF transcript expression is associated with chromosome 9p21 variants linked to atherosclerosis. PLoS One 4(4): e5027, 2009. PMID: 19343170. DOI: 10.1371/journal.pone.0005027

23 Gu F, Pfeiffer RM, Bhattacharjee S, Han SS, Taylor PR, Berndt S, Yang H, Sigurdson AJ, Toro J, Mirabello L, Greene MH, Freedman ND, Abnet CC, Dawsey SM, Hu N, Qian YL, Ding $\mathrm{T}$, Brenner AV, Garcia-Closas M, Hayes R, Brinton LA, LIssowska J, WentzensenN, Kratz C, Moore LE, Ziegler RG, Chow WH, Savage SA, Burdette L, Yeager M, Chanock SJ, Chatterjee N, Tucker MA, Goldstein AM and Yang XR: Common genetic variants in the $9 \mathrm{p} 21$ region and their associations with multiple tumors. Br J Cancer 108(6): 13781386, 2013. PMID: 23361049. DOI: 10.1038/bjc.2013.7

24 Stacey SN, Sulem P, Masson G, Gudjonsson SA, Thorleifsson G, Jakobsdottir M, Sigurdsson A, Gudbjartsson DF, Sigurgerirsson B, Benediktsdottir KR, Thorisdottir K, Ragnarsson R, Scherer D, Hemminki K, Rudnai P, Gurzau E, Koppova K, Botella-Estrada R, Soriano V, Juberias P, Saez B, Stefansson K: New common variants affecting susceptibility to basal cell carcinoma. Nat Genet 41(8): 909-914, 2009. PMID: 19578363. DOI: 10.1038/ng.412
25 Pasmant E, Sabbagh A, Masliah-Planchon J, Ortonne N, Laurendeau I, Melin L, Ferkal S, Hernandez L, Leroy K, Valeyrie-Allanore L, Parfait B, Vidaud D, Bieche I, Lantieri L, Wolkenstein P, Vidaud M and NF France Network: Role of noncoding RNA ANRIL in genesis of plexiform neurofibromas in neurofibromatosis type 1. J Natl Cancer Inst 103(22): 17131722, 2011. PMID: 22034633. DOI: 10.1093/jnci/djr416

26 Royds JA, Pilbrow AP, Ahn A, Morrin HR, Frampton C, Russell IA, Moravec CS, Sweet WE, Tang WH, Currie MJ, Hung NA and Slatter TL: The rs 11515 polymorphism is more frequent and associated with aggressive breast tumors with increased anril and decreased p16 (ink4a) expression. Front Oncol 5: 306, 2016. PMID: 26835415. DOI: 10.3389/fonc.2015.00306

27 Poi MJ, Li J, Sborov DW, VanGundy Z, Cho YK, Lamprecht M, Pichiorri F, Phelps MA and Hofmeister CC: Polymorphism in ANRIL is associated with relapse in patients with multiple myeloma after autologous stem cell transplant. Mol Carcinog 56(7): 17221732, 2017. PMID: 28150872 . DOI: $10.1002 / \mathrm{mc} .22626$

28 Grambsch P and Therneau T: Proportional hazards tests and diagnostics based on weighted residuals. Biometrika 81: 515526, 1994. DOI: $10.2307 / 2337123$

29 Fine JP and Gray RJ: A proportional hazards model for subdistribution of a competing risk. JASA 94: 496-509, 1999. DOI: $10.2307 / 2670170$

30 Veintramuthu S, Parthasarathy R, Mathew S, John S, Kandra Kumar V and Rodrigues PA: Comorbidities and its relation to performance status and estimated survival rate among cancer patients. J Res Pharm 23(2): 304-314, 2019. DOI: 10.12991/jrp. 2019.138

31 Lin L, Gu ZT, Chen WH and Cao KJ: Increased expression of the long non-coding RNA ANRIL promotes lung cancer cell metastasis and correlates with poor prognosis. Diagn Pathol 10: 14, 2015. PMID: 25889788. DOI: 10.1186/s13000-015-0247-7

32 Drexler HG: Review of alterations of the cyclin-dependent kinase inhibitor INK4 family genes p15, p16, p18, and p19 in human leukemia-lymphoma cells. Leukemia 12(6): 845-859, 1998. PMID: 9639410. DOI: 10.1038/sj.leu.2401043

33 Hirai H, Ogawa S, Hangaishi T, Takahashi T, Kurokawa M, Mitani K, Ueda R and Yazaki Y: Recent progress in molecular mechanisms of leukemogenesis: the cyclin-dependent kinase 4inhibitor gene in human leukemias. Leukemia 11: 358-360, 1997. PMID: 9209389.
Received July 26, 2020

Revised August 6, 2020

Accepted August 7, 2020 